Muhammad Abbas Ahmad Zaini* and Raidah Md. Sudi

\title{
Valorization of human hair as methylene blue dye adsorbents
}

https://doi.org/10.1515/gps-2017-0021

Received February 8, 2017; accepted June 21, 2017; previously published online September 12, 2017

Abstract: The present study was aimed at evaluating the performance of human hair as adsorbents for methylene blue (MB) dye removal. Human hair was treated using 0.1 M potassium hydroxide ( $\mathrm{KOH}$ ) and $0.1 \mathrm{M}$ nitric acid, and the adsorbents were characterized for specific surface area and surface chemistry. The basic-treated human hair adsorbent (BH) exhibits a specific surface area of $3.51 \mathrm{~m}^{2} / \mathrm{g}$, which is relatively higher than the acid-treated $(\mathrm{AH})$ and untreated $(\mathrm{UH})$ counterparts. The equilibrium data of all adsorbents obeyed the S-shaped isotherm, suggesting a cooperative adsorption. The $\mathrm{BH}$ displays a maximum capacity of $13.5 \mathrm{mg} / \mathrm{g}$, while a comparable capacity of $3.4 \mathrm{mg} / \mathrm{g}$ was recorded by $\mathrm{AH}$ and $\mathrm{UH}$. The adsorption of MB by $\mathrm{BH}$ increased with increasing $\mathrm{pH}$. Based on the equilibrium and kinetics data, the adsorption of $\mathrm{MB}$ onto $\mathrm{BH}$ is proposed to have the following mechanisms: (i) external diffusion, (ii) intraparticle diffusion, and (iii) cooperative adsorption. In addition, the $\mathrm{MB}$ adsorption at a concentration of $20 \mathrm{mg} / \mathrm{l}$ is endothermic and spontaneous with temperature increasing from $35^{\circ} \mathrm{C}$ to $55^{\circ} \mathrm{C}$. A basic treatment of human hair using $\mathrm{KOH}$ yields a promising adsorbent for dye in wastewater treatment.

Keywords: adsorbent; basic treatment; human hair; methylene blue (MB); S-shaped isotherm.

*Corresponding author: Muhammad Abbas Ahmad Zaini, Faculty of Chemical and Energy Engineering and Centre of Lipids Engineering and Applied Research (CLEAR), Ibnu-Sina Institute for Scientific and Industrial Research (ISI-SIR), Universiti Teknologi Malaysia, 81310 UTM Johor Bahru, Johor, Malaysia,

e-mail:abbas@cheme.utm.my

Raidah Md. Sudi: Faculty of Chemical and Energy Engineering and Centre of Lipids Engineering and Applied Research (CLEAR), Ibnu-Sina Institute for Scientific and Industrial Research (ISI-SIR), Universiti Teknologi Malaysia, 81310 UTM Johor Bahru, Johor, Malaysia

\section{List of abbreviations}

$\begin{array}{ll}\mathrm{AH} & \text { nitric acid-treated human hair adsorbent } \\ \mathrm{BH} & \text { potassium hydroxide-treated human hair adsorbent } \\ \mathrm{EDS} & \text { energy dispersive spectrometry } \\ \mathrm{HCl} & \text { hydrochloric acid } \\ \mathrm{HNO}_{3} & \text { nitric acid } \\ \mathrm{H}_{2} \mathrm{SO}_{4} & \text { sulfuric acid } \\ \mathrm{KOH} & \text { potassium hydroxide } \\ \mathrm{MB} & \text { methylene blue } \\ \mathrm{MS} & \text { Microsoft } \\ \mathrm{NaOH} & \text { sodium hydroxide } \\ \text { pH } & \text { potential of hydrogen } \\ \text { pI } & \text { isoelectric point } \\ R^{2} & \text { coefficient of determination } \\ \mathrm{SSE} & \text { sum of squared error } \\ \mathrm{UH} & \text { untreated human hair adsorbent }\end{array}$

\section{List of symbols}

c

$C_{0}$

$C_{\mathrm{e}}$

$C_{e, \mathrm{a}}$

$C_{\mathrm{t}}$

$\mathrm{d} C_{\mathrm{t}} / \mathrm{d} t$

K

$K_{\mathrm{p}}$

$k_{\mathrm{S}}^{\mathrm{p}}$

$k_{1}$

$k_{2}$

$m_{\mathrm{e}}$

$m_{\mathrm{t}}$

$Q_{\mathrm{m}}$

$q_{\mathrm{e}}$

$q$

$R$

$T$

$t$

V

$\Delta G$

$\Delta H$

$\Delta S$

$\pi$

$-\mathrm{COOH}$

$-\mathrm{NH}$

$-\mathrm{NH}_{2}$ adsorption affinity (1/mg)

intercept of the intraparticle diffusion model $(\mathrm{mg} / \mathrm{g})$

initial concentration $(\mathrm{mg} / \mathrm{l})$

equilibrium concentration $(\mathrm{mg} / \mathrm{l})$

amount of dye adsorbed $(\mathrm{mg} / \mathrm{l})$

concentration at time $t(\mathrm{mg} / \mathrm{l})$

gradient of concentration with time $(\mathrm{mg} / \mathrm{l} \cdot \mathrm{h})$

equilibrium constant

the intraparticle diffusion rate constant $\left(\mathrm{mg} / \mathrm{g} \cdot \mathrm{h}^{0.5}\right)$

the $\mathrm{S}$-shaped kinetics rate constant $\left(\mathrm{h}^{-1}\right)$

the pseudo-first-order rate constant $\left(\mathrm{h}^{-1}\right)$

the pseudo-second-order rate constant $(\mathrm{g} / \mathrm{mg} \cdot \mathrm{h})$

mass of the adsorbent $(\mathrm{g}$ )

midpoint equilibrium concentration (mg/l)

midpoint of time (h)

maximum adsorption capacity $(\mathrm{mg} / \mathrm{g})$

equilibrium adsorption $(\mathrm{mg} / \mathrm{g})$

adsorption at time $t(\mathrm{mg} / \mathrm{g})$

the gas constant $(8.314 \mathrm{~J} / \mathrm{mol} \cdot \mathrm{K})$

temperature $(\mathrm{K})$

time (h)

volume of the solution (l)

Gibbs free energy $(\mathrm{J} / \mathrm{mol})$

enthalpy $(\mathrm{J} / \mathrm{mol})$

entropy $(\mathrm{J} / \mathrm{mol} \cdot \mathrm{K})$

delocalized $\pi$-electrons

carboxylic group

amine group

amino group 


$\begin{array}{ll}-\mathrm{OH} & \text { phenolic group } \\ =\mathrm{O} & \text { lactonic group } \\ -\mathrm{S}-\mathrm{S}- & \text { disulfide bond. }\end{array}$

\section{Introduction}

There is a growing concern over the abundance of human hair waste in landfills that sometimes choke and disrupt the drainage system. Human hair is a biological waste with slow degradation rate. During the stages of natural decomposition, it releases ammonia and nitrogen. On the other hand, direct burning of human hair produces toxic gases such as ammonia, hydrogen sulfide, sulfur dioxide, and other volatiles like phenols, nitriles, pyrroles, and pyridines that bring about foul odor [1]. Because human hair waste can become a threat to the environment, an alternative solution to waste disposal is, therefore, imperative to be sought.

Human hair contains up to $95 \%$ protein that is mainly composed of polymers of amino acids such as keratin and cystine [2]. Keratin gives hair the strength, flexibility, durability, and functionality. Hydrogen bonds between the carboxylic $(-\mathrm{CO}-\mathrm{OH})$ and amine $(-\mathrm{NH})$ groups provide stabilization to the hair structures [3]. These functional groups could also act as active sites for the removal of water pollutants through coordination mechanism and electrostatic attraction $[4,5]$. Human hair is one of the highest nitrogen-containing organic materials, and some has been commercially converted into fertilizer [1]. Human hair is known for its unique properties, i.e. high tensile strength, slow degradation rate, scaly surface, thermal insulation, and interactions with water and oils [1]. In view of these traits, human hair can be considered as an excellent candidate of natural adsorbent for water pollutants removal $[4,6]$.

Human hair has high affinity for oils, and can attract certain chemical compounds from the solution. Ifelebuegu et al. [7] reported the adsorption of $9300 \mathrm{mg} / \mathrm{g}$ vegetable oil by detergent-washed human hair. Mahdavian [8] reported the removal of $33 \mathrm{mg} / \mathrm{g}$ lead(II) using $\mathrm{NaOH}$-treated human hair. Human hair was also used for the removal of basic (cationic) dyes [9, 10]. Hashem et al. [9] reported a $16.9 \mathrm{mg} / \mathrm{g}$ removal of basic blue 69 by the untreated human hair. In general, the adsorption of heavy metals and cationic dyes onto hair-based adsorbent involves the interaction with the unpaired electrons in the nitrogen and oxygen atoms, by which the electrochemical bonds are formed between the oppositely charged substances [5, 11]. Specifically, the presence of amino and hydroxyl groups offers natural negative charges on the hair surface for the adsorption of positively charged pollutants.

Dyes are often manufactured using chemicals that are highly toxic [12]. Methylene blue (MB) is a commonly used basic dye in textile industry because of its bright color and high intensity. It is very soluble in water, and highly visible even in trace amount [12]. The presence of dye in water bodies disrupts the penetration of sunlight, retards the photosynthesis process, thus decreasing the oxygen solubility, and consequently upsetting the aquatic ecosystem. Excessive exposure to MB can cause serious health problems such as increased heart rate, vomiting, jaundice, shock, Heinz body formation, quadriplegia, cyanosis, and tissue necrosis [12, 13]. Dye is purposely designed to withstand the chemical and microbial attacks, hence its removal from water has become a challenging task [14].

A number of natural materials have been tested as MB adsorbents. These include Aleurites moluccana seed [15], $\mathrm{NaOH}$-treated orange peel [16], Prosopis sicigera L. wood [17], $\mathrm{H}_{2} \mathrm{SO}_{4}$-treated Areca triandra palm shell [18], chemically treated human hair [9], NaOH-treated pine nut shell [19], and chemically modified Cocos nucifera L. [20]. To the best of our knowledge, the adsorptive properties of the basic-treated human hair for dye removal are still not available in much of the published literature. To narrow down the gap, the present work was aimed to challenge the MB adsorption by three human hair-based adsorbents, namely untreated, acid-treated, and basic-treated. Potassium hydroxide $(\mathrm{KOH})$ and nitric acid $\left(\mathrm{HNO}_{3}\right)$ were used in the treatment of human hair. The removal performance was evaluated based on the dye concentration, solution $\mathrm{pH}$, contact time, and temperature. The findings were discussed and the removal mechanisms were proposed.

\section{Materials and methods}

Human hair residue was obtained from local hair salon located at the Johor state of Malaysia. All chemicals used (MB dye, KOH, sodium hydroxide, hydrochloric acid, and $\mathrm{HNO}_{3}$ ) were of analytical-grade reagents.

\subsection{Preparation and characterization of human hair adsorbents}

Human hair was cut to a size of approximately $2 \mathrm{~cm}$. Then it was soaked in distilled water, and boiled for $15 \mathrm{~min}$ to remove impurities. This step was repeated until the washed water becomes clear. Then the sample was oven-dried at $110^{\circ} \mathrm{C}$ for $24 \mathrm{~h}$. After that, the dried sample was immersed in $0.1 \mathrm{M} \mathrm{HNO}_{3}$ for $24 \mathrm{~h}$, and then it was washed repeatedly using hot water until there is no further change in the 
solution $\mathrm{pH}$. Similar step was repeated for the basic-treated human hair adsorbent using $0.1 \mathrm{M} \mathrm{KOH}$. No noticeable change in the shape or form of human hair was observed upon the treatment strategies. The three adsorbents, i.e. untreated, acid-treated, and basic-treated were designated as $\mathrm{UH}, \mathrm{AH}$ and $\mathrm{BH}$, respectively. All adsorbents were dried prior to use.

Human hair was characterized for its thermal behavior using a Perkin-Elmer thermogravimetric analyzer (TGA 7). The measurement was carried out under a nitrogen flow of $20 \mathrm{ml} / \mathrm{min}$ at a heating rate of $10^{\circ} \mathrm{C} / \mathrm{min}$. All adsorbents were analyzed for specific surface area, surface functional groups, and elemental composition. The measurement of single-point specific surface area was performed by BrunauerEmmett-Teller method using a Micromeritics surface analyzer (Gemini 2360). The presence of surface functional groups was determined using a Shimadzu spectrometer (IRTracer-100). The energy dispersive spectrometry (EDS) was performed to obtain the elemental composition of human hair using a Hitachi field emission scanning electron microscope coupled with an EDS detector (SU8020). The measurements were performed twice and the average data were reported.

\subsection{Adsorption studies}

Thirty milligrams of the adsorbent was added in a series of conical flasks containing $30 \mathrm{ml}$ of MB solution with concentrations between 2 and $50 \mathrm{mg} / \mathrm{l}$. The solution $\mathrm{pH}$ was not adjusted, and was measured as $\mathrm{pH} 5.7 \pm 0.1$. The control solution was prepared for reference. The mixture was allowed to equilibrate at room temperature for $72 \mathrm{~h}$. After that, the supernatant was taken out for concentration measurement using a Dynamica visible spectrophotometer (Halo Vis -10 ) at a wavelength of $564 \mathrm{~nm}$. The calibration was determined as a.u. $=0.0176 \times$ concentration, with $R^{2}=0.991$ for MB concentrations between 2 and $25 \mathrm{mg} / \mathrm{l}$. The capacity of adsorption at equilibrium, $q_{\mathrm{e}}(\mathrm{mg} / \mathrm{g})$ was calculated as $q_{\mathrm{e}}=\left(C_{\mathrm{o}}-C_{\mathrm{e}}\right) \times(\mathrm{V} / \mathrm{m})$, where $C_{\mathrm{o}}$ and $C_{\mathrm{e}}(\mathrm{mg} / \mathrm{l})$ are the initial concentration and concentration at equilibrium, respectively, $m(\mathrm{~g})$ is the adsorbent mass, and $V(\mathrm{l})$ is the volume of solution. The removal efficiency (\%) was calculated as $\left(C_{\mathrm{o}}-C_{\mathrm{e}}\right) \times 100 / C_{\mathrm{o}}$. The effect of concentration was used to screen the removal performance by the three adsorbents; the resulting data were used to select the one used for the subsequent parameters evaluation which is described as follows.

The effect of $\mathrm{pH}$ was evaluated at MB concentrations of 5 and $10 \mathrm{mg} / \mathrm{l}$, in which the solution $\mathrm{pH}$ was adjusted between $\mathrm{pH} 2$ and 10 using $0.1 \mathrm{M} \mathrm{NaOH}$ or $0.1 \mathrm{M} \mathrm{HCl}$. The concentrations were selected based on the equilibrium curve that demonstrates appreciable adsorption affinity. The control solution with the same adjusted $\mathrm{pH}$ was prepared for reference. The mixture was allowed to reach the equilibrium for $72 \mathrm{~h}$, after which the concentration and $\mathrm{pH}$ at the equilibrium were measured.

Three concentrations were selected for the rate of adsorption and the effect of temperature based on appreciable adsorption affinity and maximum capacity. Thirty milligrams of human hair adsorbent was brought into intimate contact with a series of $30 \mathrm{ml} \mathrm{MB}$ solution of known concentrations. The supernatant was withdrawn from the solution at the preset time intervals for the concentration measurement. The adsorption capacity at time $t, q_{\mathrm{t}}$ was calculated as $q_{\mathrm{t}}=\left(C_{\mathrm{o}}-C_{\mathrm{t}}\right) \times(\mathrm{V} / \mathrm{m})$, where $C_{\mathrm{t}}(\mathrm{mg} / \mathrm{l})$ is the measured MB concentration at time $t$. The adsorption of MB at varying temperatures was performed by adjusting the water bath temperature at $35^{\circ} \mathrm{C}, 45^{\circ} \mathrm{C}$ and $55^{\circ} \mathrm{C}$. The control solution at the same tested temperature was employed for reference. Other experimental steps are identical as described for the effect of concentration.

\section{Results and discussion}

\subsection{Characteristics of human hair adsorbents}

Figure 1 displays the thermal profile of human hair. The initial weight loss of $7 \%$ from $33^{\circ} \mathrm{C}$ to $130^{\circ} \mathrm{C}$ is due to the release of the physically adsorbed water. The sharp peaks at $249^{\circ} \mathrm{C}$ and $345^{\circ} \mathrm{C}$ with $50 \%$ weight loss could be attributed to the denaturation of keratin polypeptide chains that make up the morphologies and structures of human hair [21]. Denaturation is a process whereby the proteins lose their original structure, become more simplified, and start to degrade with increasing temperature. The degradation of carbonic chains takes place at a temperature range of $345^{\circ} \mathrm{C}-470^{\circ} \mathrm{C}$ [22], while a complete degradation of keratin and hair structures was observed at $700^{\circ} \mathrm{C}$ with residual of $20 \%$.

Table 1 shows the characteristics of human hair adsorbents. The adsorbents exhibit similar yield of $92 \pm 1 \%$

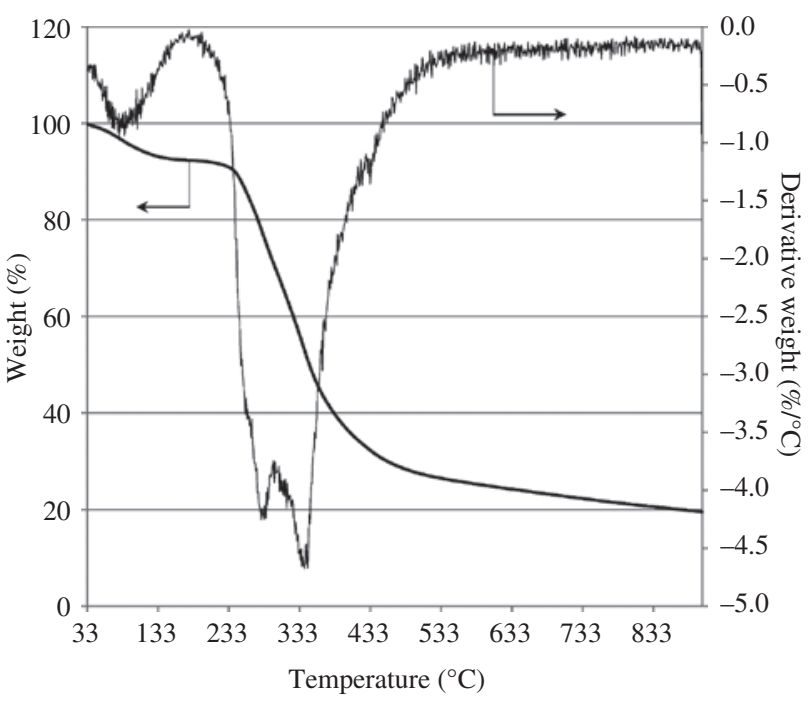

Figure 1: Thermogravimetric curve of human hair.

Table 1: Characteristics of human hair adsorbents.

\begin{tabular}{lrrrrrr}
\hline Sample & Yield (\%) & pH & $\begin{array}{r}\text { Surface } \\
\text { area }\left(\mathrm{m}^{2} / \mathbf{g}\right)\end{array}$ & & \multicolumn{2}{r}{ EDS (wt\%) } \\
\cline { 5 - 7 } & & & & Carbon & Oxygen & Sulfur \\
\hline UH & 93.0 & 5.43 & 1.36 & 72.3 & 26.5 & 1.2 \\
AH & 92.0 & 4.95 & 1.96 & 71.6 & 26.2 & 2.0 \\
BH & 91.2 & 5.44 & 3.51 & 67.5 & 31.0 & 1.4 \\
\hline
\end{tabular}


with $\mathrm{pH}$ varying between 4.95 and 5.44 . The basic-treated human hair adsorbent (BH) displays a higher specific surface area of $3.51 \mathrm{~m}^{2} / \mathrm{g}$ upon treatment with $\mathrm{KOH}$, while a small increase was observed for $\mathrm{HNO}_{3}$-treated one (AH). It is suggested that the basic treatment could be effective to flush the impurities (probably trace oils) on the hair surface, thus exposing the hair structures and also the functional groups. This could be supported by a slight decrease in yield, and an increase in oxygen content (EDS data) for $\mathrm{BH}$.

The infrared penetrates the outer surface of hair, known as cuticle that is primarily composed of cystine, and other amino acids which are not usually found in alpha helical polypeptides [21]. Cystine is an oxidized dimer of amino acid. It contains a disulfide bond (-S-S-) that binds two cystine molecules together, carboxyl group (-CO-OH), and amino group (- $\left.\mathrm{NH}_{2}\right)$.

From the Fourier transform infrared analysis, all adsorbents exhibit similar spectra signifying the presence of identical surface functional groups. The broad and medium intensity band ranging from 3600 to $3000 \mathrm{~cm}^{-1}$ corresponds to the stretches of carboxylic acid (-CO$\mathrm{OH})$, phenolic $(-\mathrm{OH})$, and amino acid $\left(-\mathrm{NH}_{2}\right)$ groups. The peaks located at $1640 \mathrm{~cm}^{-1}$ (Amide I), $1520 \mathrm{~cm}^{-1}$ (Amide II), $1240 \mathrm{~cm}^{-1}$ (Amide III), and $900 \mathrm{~cm}^{-1}$ (Amide V) are the characteristics of amino acids, while peaks at $1040 \mathrm{~cm}^{-1}$, $1080 \mathrm{~cm}^{-1}$, and $1120 \mathrm{~cm}^{-1}$ are associated with distinct sulfur groups of cystine. The presence of these functional groups is in agreement with the typical chemical constituents of human hair. The variation in peak intensity between the treated human hair-based adsorbents and the untreated one (UH) was not observed.

\subsection{Adsorption equilibrium}

Figure 2 shows the effect of initial concentration of MB dye on the adsorption performance of human hair as adsorbents. Generally, the adsorption capacity increased with increasing concentration. All adsorbents exhibit a concentration-dependent adsorption due to concentration gradient that provides the driving force to suppress the adsorbent mass transfer resistance for adsorption to take place. To a point of surface saturation, the active sites can no longer accommodate the dye molecules, and consequently the removal capacity begins to level off. The adsorption capacity was found to be in the order of $\mathrm{BH}>\mathrm{UH}>\mathrm{AH}$. This could be explained by the characteristics of $\mathrm{BH}$ as displayed in Table 1. BH shows a maximum removal efficiency of $80 \%\left(q_{\mathrm{e}}=10 \mathrm{mg} / \mathrm{g}\right)$ at $C_{0}=13 \mathrm{mg} / \mathrm{l}$, while a higher capacity of $14 \mathrm{mg} / \mathrm{g}$ was

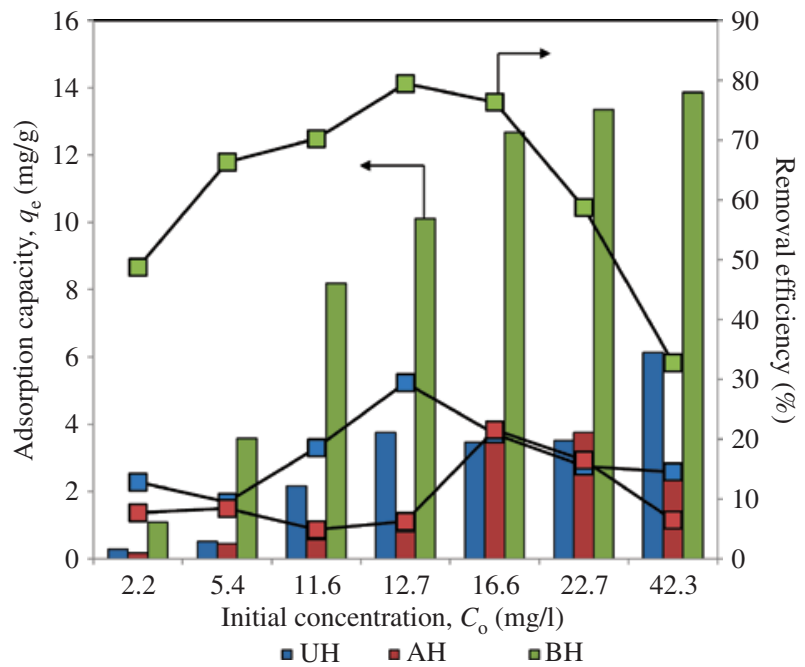

Figure 2: Effect of concentration on methylene blue removal by human hair adsorbents (bars: adsorption capacity; lines: removal efficiency).

obtained at $C_{0}=42 \mathrm{mg} / \mathrm{l}$ with a decreased efficiency of $33 \%$. The decrease in the removal efficiency is linked with the increase in residual concentration upon equilibrium due to the decrease of vacant sites with increasing concentration. Similar pattern was also demonstrated by $\mathrm{AH}$ and $\mathrm{UH}$, with maximum removal efficiency of $22 \%\left(q_{\mathrm{e}}=3.6 \mathrm{mg} / \mathrm{g}, C_{\mathrm{o}}=17 \mathrm{mg} / \mathrm{l}\right)$ and $30 \%\left(q_{\mathrm{e}}=3.8 \mathrm{mg} / \mathrm{g}\right.$, $\left.C_{\mathrm{o}}=13 \mathrm{mg} / \mathrm{l}\right)$, respectively.

Figure 3 shows the equilibrium curves of MB adsorption onto human hair adsorbents. The concave downward pattern indicates a favorable MB adsorption onto human

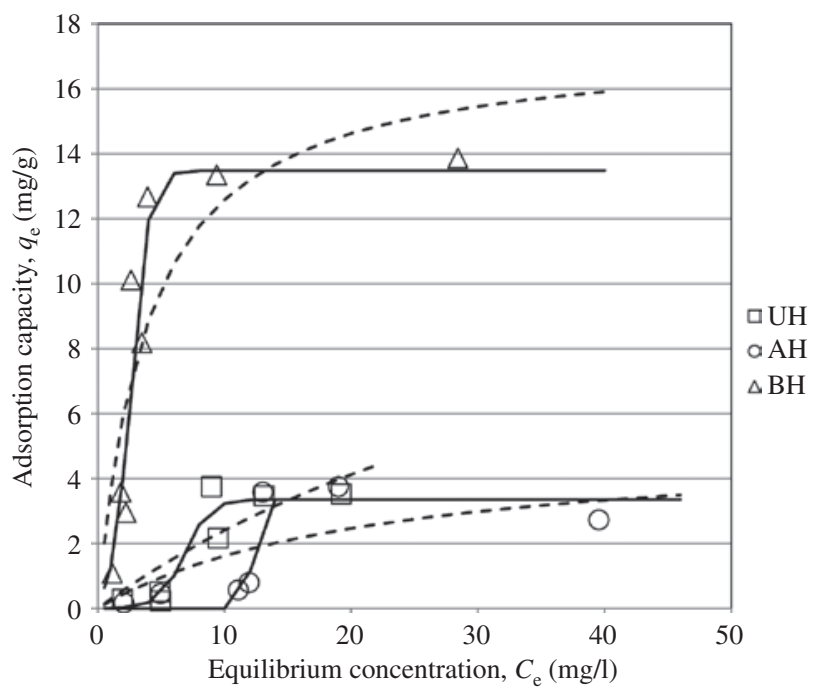

Figure 3: Equilibrium adsorption of methylene blue onto human hair adsorbents (lines were predicted by, solid: S-shaped isotherm; dashed: Langmuir isotherm). 
hair adsorbents. The maximum adsorption capacity of $\mathrm{BH}$ was recorded as $13.5 \mathrm{mg} / \mathrm{g}$, while $\mathrm{AH}$ and $\mathrm{UH}$ shared a similar capacity of $3.4 \mathrm{mg} / \mathrm{g}$. BH exhibits a comparable removal performance with orange peel (surface area $=1.17 \mathrm{~m}^{2} / \mathrm{g}, Q_{\mathrm{m}}=18.3 \mathrm{mg} / \mathrm{g}$ ) [16] and Prosopis sicigera L. wood (surface area $=121 \mathrm{~m}^{2} / \mathrm{g}, Q_{\mathrm{m}}=25.1 \mathrm{mg} / \mathrm{g}$ ) [17].

The adsorption data were fitted into two models, namely Langmuir [Eq. (1)] [23] and S-shaped isotherm [(Eq. (2)], as follows,

$$
\begin{gathered}
q_{\mathrm{e}}=\frac{Q_{\mathrm{m}} b C_{\mathrm{e}}}{1+b C_{\mathrm{e}}} \\
q_{\mathrm{e}}=\frac{Q_{\mathrm{m}}}{1+e^{-b\left(C_{\mathrm{e}}-m_{\mathrm{e}}\right)}},
\end{gathered}
$$

where $Q_{\mathrm{m}}(\mathrm{mg} / \mathrm{g})$ is the maximum adsorption capacity, $b(\mathrm{l} / \mathrm{mg})$ is the adsorption affinity, and $m_{\mathrm{e}}(\mathrm{mg} / \mathrm{l})$ is the midpoint equilibrium concentration. The isotherm constants were solved by nonlinear regression using Solveradd in MS Excel for the least sum-of-squared error (SSE) that yields the optimum coefficient of determination, $R^{2}$. Table 2 summarizes the values of isotherm constants. The adsorption data fitted well into S-shaped isotherm. This is true for all adsorbents studied. It implies that the adsorption did not follow an ordinary Langmuir isotherm that describes a monolayer adsorption onto homogeneous adsorbent surface [23]. Rather, the S-shaped isotherm suggests a cooperative adsorption, whereby the already adsorbed dye molecules formed a layer to attract the mobile molecules in the bulk solution to be captured as well [24]. It is evident from Figure 3, where the uptake capacity is initially small at low equilibrium concentration to a point where the capacity displays a sudden steep increase with a small increase in concentration which renders a maximum value of adsorption capacity.

The S-shaped isotherm satisfactorily predicts the maximum adsorption capacity from the experimental data (Table 2). Despite having an identical maximum capacity, $\mathrm{AH}$ reaches the same point at a higher equilibrium concentration compared to UH. It could be due to the protonated surface of $\mathrm{AH}\left(\mathrm{pH}=5.0, \mathrm{pH}_{\mathrm{e}}=5.2\right)$ that somewhat hinders and drives away the positively charged MB molecules at lower concentration, leading to a lower removal efficiency. However, this was somewhat overcome as the concentration increases because of the increase in the interaction probabilities.

The adsorption of MB onto human hair could be driven by surface functional groups. During $\mathrm{KOH}$ treatment, oil covering the hair surface is removed, thus exposing the surface functional groups and thereby increasing the specific surface area. The main component in hair is cystine, while the probable functional groups for adsorption are amine $\left(-\mathrm{NH}_{2}\right)$, phenolic $(-\mathrm{OH})$, and lactonic $(=0)$. Amine has one lone pair electron, while phenolic and lactonic possess two lone pair electrons. Hence, they are all electron donating groups that are prone to release electron to the oxidizing agent or electron withdrawer/acceptor (MB). However, based on the electronegativity rule, oxygen is more electronegative than nitrogen that implies a stronger hold of electrons by oxygen. Hence, it is presumed that the adsorption of methylene is much easier on the amine groups compared to the oxygen groups. The following mechanisms can be proposed for MB adsorption onto human hair.

$$
\begin{aligned}
& -\mathrm{NH}_{2}+\mathrm{MB}^{+} \rightarrow-\mathrm{NH}_{2}^{+}-\mathrm{MB} \\
& -\mathrm{OH}+\mathrm{MB}^{+} \rightarrow-\mathrm{OH}^{+}-\mathrm{MB} .
\end{aligned}
$$

Figure 4 shows the effect of solution $\mathrm{pH}$ on $\mathrm{MB}$ adsorption onto basic-treated human hair adsorbent (BH). For the two concentrations studied, a similar pattern of $\mathrm{pH}$-dependent adsorption was demonstrated, in which the adsorption of MB increased with increasing solution $\mathrm{pH}$. The trend is more pronounced for $C_{\mathrm{o}}=10 \mathrm{mg} / \mathrm{l}$. This could be attributed to the isoelectric point (pI) of human hair which is in the range of 2.45-3.17 [25]. The solution $\mathrm{pH}$ affects the adsorbent surface charge through the dissociation of functional groups, and the degree of ionization of dye molecule. The surface charge of human hair is positive when the solution $\mathrm{pH}$ is below $\mathrm{pI}$ due to the

\begin{tabular}{|c|c|c|c|c|c|c|c|c|c|c|}
\hline \multirow[t]{2}{*}{ Adsorbent } & \multirow{2}{*}{$\begin{array}{l}\text { Equilibrium } \\
\qquad \mathrm{pH}, \mathrm{pH}_{\mathrm{e}}\end{array}$} & \multicolumn{4}{|c|}{ Langmuir } & \multicolumn{5}{|c|}{ S-shaped } \\
\hline & & $Q_{m}(\mathrm{mg} / \mathrm{g})$ & $b(\mathrm{l} / \mathrm{mg})$ & SSE & $R^{2}$ & $Q_{\mathrm{m}}(\mathrm{mg} / \mathrm{g})$ & $b(\mathrm{l} / \mathrm{mg})$ & $m_{\mathrm{e}}(\mathrm{mg} / \mathrm{l})$ & SSE & $R^{2}$ \\
\hline UH & $5.4 \pm 0.1$ & 14.3 & 0.0203 & 4.69 & 0.726 & 3.36 & 1.02 & 6.83 & 1.67 & 0.896 \\
\hline $\mathrm{AH}$ & $5.2 \pm 0.2$ & 5.16 & 0.0457 & 7.66 & 0.496 & 3.35 & 7.31 & 12.1 & 1.16 & 0.948 \\
\hline $\mathrm{BH}$ & $6.0 \pm 0.1$ & 17.4 & 0.259 & 51.7 & 0.734 & 13.5 & 1.45 & 2.58 & 21.3 & 0.883 \\
\hline
\end{tabular}
protonated surface by hydrogen ions, while the surface becomes negatively charged when the solution $\mathrm{pH}$ is

Table 2: Constants of isotherm models. 


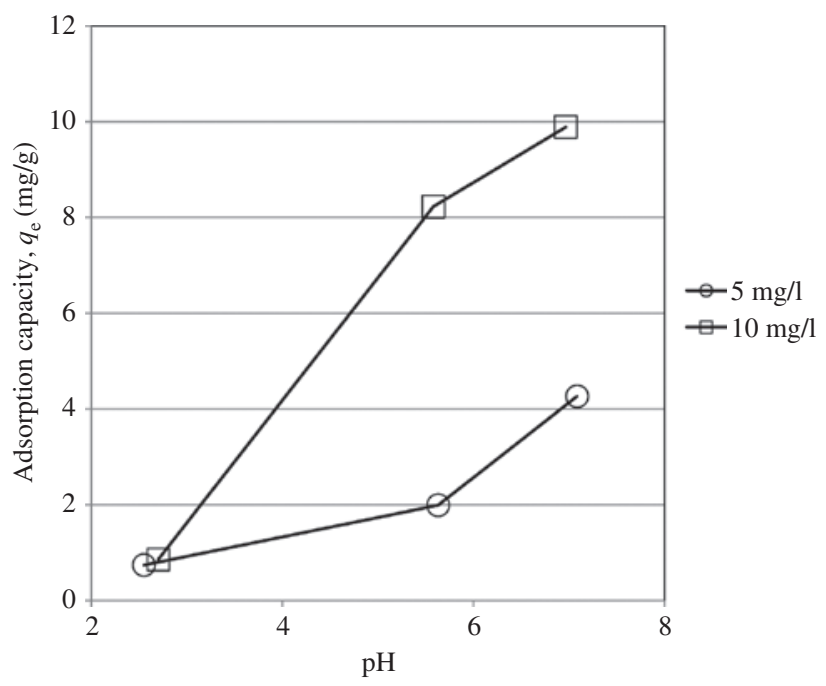

Figure 4: Effect of solution $\mathrm{pH}$ on the removal of methylene blue by basic-treated human hair adsorbent.

greater than pI. As a result, the electrostatic interaction/ attraction between the deprotonated surface and the positively charged MB molecules increased with increasing solution $\mathrm{pH}$ [26]. However, extra caution should be taken as the increase of solution $\mathrm{pH}$ could in some way affect the wavelength and density of the solution, thus nullifying the concentration value (e.g., for $\mathrm{pH} 10$, before $\mathrm{pH}$ adjustment $C_{\mathrm{o}}=10 \mathrm{mg} / \mathrm{l}$, after $\mathrm{pH}$ adjustment $C_{\mathrm{o}}=18 \mathrm{mg} / \mathrm{l}$ ).

\subsection{Rate of adsorption}

Figure 5 displays the rate of MB adsorption by $\mathrm{BH}$ at three selected concentrations, i.e. 5,13 , and $25 \mathrm{mg} / \mathrm{l}$. A rapid adsorption was observed in the first $2.5 \mathrm{~h}$, after which the removal capacity starts to level-off at different values depending on the concentrations used. The initial fast removal is due to high concentration gradient and unoccupied active sites on the adsorbent surface. As the MB molecules start to lodge on the active sites, the remaining molecules in the bulk solution become lesser thus decreasing the rate of adsorption $\left(\mathrm{d} C_{\mathrm{t}} / \mathrm{d} t \rightarrow 0\right)$.

The quasi-equilibrium was observed at around $6 \mathrm{~h}$, with $q_{\mathrm{t}}=13.5,8$, and $3.5 \mathrm{mg} / \mathrm{g}$ with descending concentrations. Later at $t>17 \mathrm{~h}$, a jump in $\mathrm{MB}$ adsorption was detected for concentrations 13 and $25 \mathrm{mg} / \mathrm{l}$, thus creating an additional adsorption isotherm. The $q_{\mathrm{e}}$ values obtained after $17 \mathrm{~h}$ are in agreement with the data shown in Figures 2 and 3. From Figure 5, it can be generalized that the actual equilibrium for higher concentrations could be attained at $t>17 \mathrm{~h}$, while a shorter period may be sufficient for lower concentrations. This also supports the hypothesis

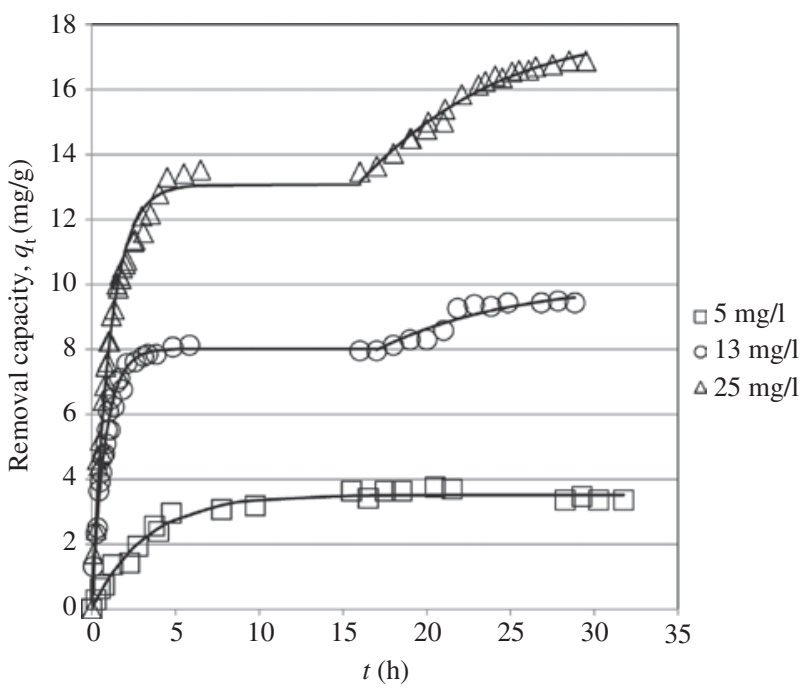

Figure 5: Rate of methylene blue adsorption by basic-treated human hair adsorbent (Lines were predicted by pseudo-first-order and S-shaped kinetics models).

of cooperative adsorption as described by the S-shaped isotherm earlier.

The kinetics data were evaluated using the pseudofirst-order [Eq. (5)] [27], pseudo-second-order [Eq. (6)] [28], and intraparticle diffusion [Eq. (7)] [29] models for the ratecontrolling steps. The kinetics models are given as follows,

$$
\begin{gathered}
q_{\mathrm{t}}=q_{\mathrm{e}}\left(1-e^{-k_{\mathrm{t}} t}\right) \\
q_{\mathrm{t}}=\frac{k_{2} q_{\mathrm{e}}^{2} t}{1+k_{2} q_{\mathrm{e}} t} \\
q_{\mathrm{t}}=K_{\mathrm{p}} t^{0.5}+C .
\end{gathered}
$$

where $q_{\mathrm{t}}(\mathrm{mg} / \mathrm{g})$ is the amount of MB adsorbed at time $t$ (h), $k_{1}\left(\mathrm{~h}^{-1}\right), k_{2}(\mathrm{~g} / \mathrm{mg} \cdot \mathrm{h})$, and $K_{\mathrm{p}}\left(\mathrm{mg} / \mathrm{g} \cdot \mathrm{h}^{0.5}\right)$ are the rate constants for the pseudo-first-order, pseudo-second-order and intraparticle diffusion models, respectively, and $C$ $(\mathrm{mg} / \mathrm{g})$ is the intercept that gives an idea about the boundary layer thickness. A generic model, namely S-shaped kinetics [Eq. (8)] was also introduced to represent an increase in the adsorption capacity at $t>17 \mathrm{~h}$ for $C_{0}=13$ and $25 \mathrm{mg} / \mathrm{l}$. It is expressed as,

$$
q_{\mathrm{t}}=\frac{q_{\mathrm{e}}}{1+e^{-k_{s}\left(t-m_{\mathrm{t}}\right)}},
$$

where $q_{\mathrm{e}}(\mathrm{mg} / \mathrm{g})$ is the equilibrium capacity, $k_{\mathrm{s}}\left(\mathrm{h}^{-1}\right)$ is the rate constant, and $m_{\mathrm{t}}(\mathrm{h})$ is the midpoint of time. All kinetics constants were solved using Solver add-in of Microsoft (MS) Excel, and the values are summarized in Table 3. 
Table 3: Constants of kinetics models.

\begin{tabular}{|c|c|c|c|}
\hline & $5 \mathrm{mg} / \mathrm{l}$ & $13 \mathrm{mg} / \mathrm{l}$ & $25 \mathrm{mg} / \mathrm{l}$ \\
\hline \multicolumn{4}{|c|}{ Pseudo-first-order ${ }^{\mathrm{a}}$} \\
\hline$q_{\mathrm{e}}(\mathrm{mg} / \mathrm{g})$ & 3.52 & 8.01 & 13.1 \\
\hline$k_{1}\left(\mathrm{~h}^{-1}\right)$ & 0.307 & 1.27 & 0.931 \\
\hline$R^{2}$ & 0.983 & 0.991 & 0.987 \\
\hline SSE & 0.570 & 1.48 & 6.01 \\
\hline \multicolumn{4}{|c|}{ Pseudo-second-order ${ }^{\mathrm{a}}$} \\
\hline$q_{\mathrm{e}}(\mathrm{mg} / \mathrm{g})$ & 3.95 & 8.85 & 15.2 \\
\hline$k_{2}(\mathrm{~g} / \mathrm{mg} \cdot \mathrm{h})$ & 0.101 & 0.203 & 0.0749 \\
\hline$R^{2}$ & 0.972 & 0.972 & 0.986 \\
\hline SSE & 0.919 & 4.21 & 5.92 \\
\hline \multicolumn{4}{|c|}{ S-shaped kinetics ${ }^{b}$} \\
\hline$q_{\mathrm{e}}(\mathrm{mg} / \mathrm{g})$ & - & 9.97 & 17.8 \\
\hline$k_{\mathrm{s}}\left(\mathrm{h}^{-1}\right)$ & - & 0.157 & 0.157 \\
\hline$m_{\mathrm{t}}(\mathrm{h})$ & - & 8.14 & 9.38 \\
\hline$R^{2}$ & - & 0.895 & 0.979 \\
\hline SSE & - & 0.516 & 0.532 \\
\hline
\end{tabular}

aConstants predicted for $0 \mathrm{~h}<t<17 \mathrm{~h}$. ${ }^{\mathrm{b}}$ Constants predicted for $t>17 \mathrm{~h}$.

From Table 3, the kinetics data for $t<17 \mathrm{~h}$ were well fitted into the pseudo-first-order model with reasonably high $R^{2}$, and a good approximation of $q_{\mathrm{e}}$ (or quasi $q_{\mathrm{e}}$ for $C_{\mathrm{o}}=13$ and $25 \mathrm{mg} / \mathrm{l}$ ) to the experimental data. The applicability of this model for the stated adsorption period indicates that the external diffusion is a significant step [4]. Also, the rate constant, $k_{1}$ increased with increasing concentration, signifying a faster adsorption at a higher concentration, and therefore the favorability of adsorption as the concentration increases. This could be seen from the change in the gradients of $q_{\mathrm{t}}$ vs. $t$ as shown in Figure 5. Depending on the availability of active sites, the adsorbent can accommodate a higher adsorbate concentration for a higher removal capacity. However, the adsorption rate is likely to slow down due to the inherent repulsion between the neighboring adsorbate molecules, and the competition for the active sites. Because of that, $k_{1}$ may as well decline at higher concentration (for $C_{0}=25 \mathrm{mg} / \mathrm{l}$ ).

For the whole adsorption period, the pseudo-firstorder model could only satisfy the adsorption data of $C_{0}=5 \mathrm{mg} / \mathrm{l}$. Hence, a generic S-shaped kinetics model was used to describe a sudden increase in the adsorption after quasi-equilibrium at $t>17 \mathrm{~h}$ for $C_{0}=13$ and $25 \mathrm{mg} / \mathrm{l}$. From Table 3, this model satisfactorily fitted the remaining data with a good prediction of $q_{\mathrm{e}}$ as that of the experimental data (Figure 5). In addition, the values of rate constant, $k_{\mathrm{s}}$ for both concentrations are comparable, but somewhat lower compared to that of $k_{1}$. It indicates that the cooperative adsorption onto the already adsorbed dye molecules occurs at a same rate, which is much slower than the initial

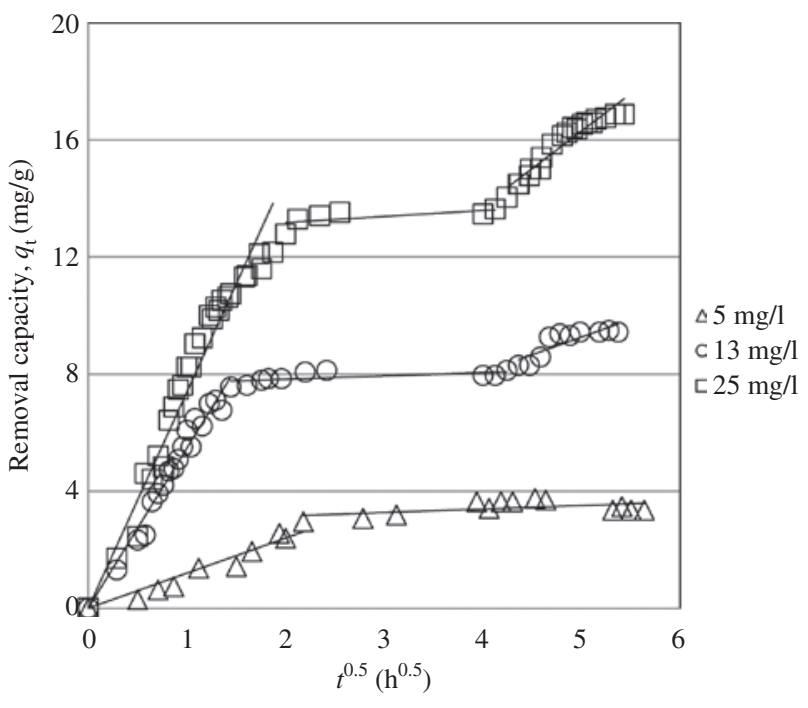

Figure 6: Intraparticle diffusion plots.

adsorption by the role of surface functional groups. The possible mechanism for the cooperative adsorption is $\pi-\pi$ interaction among the aromatic rings of MB molecules. The aromatic (benzene) ring enables the $\pi$-electrons to delocalize, thus prompting a weak attractive force towards its neighboring molecule [30]. The contact may become more effective because the already adsorbed dye molecules had lost their cationic character as a result of anchoring onto the surface functional groups at quasi-equilibrium.

Figure 6 displays the intraparticle diffusion plots. In general, all lines are not linear through origin, where each line can be split into two or three connecting lines of different slopes. Because of that, the intraparticle diffusion is not the only rate-limiting step that controls the adsorption [5]. From Figure 6, the first part of the line indicates the initial stage of adsorption, and reflects the thickness of boundary layer, while the second and the third parts represent the effect of intraparticle diffusion (adsorption) and cooperative adsorption, respectively. Hence, the rate-limiting step (slowest step) could be film diffusion to overcome the adsorbent mass transfer resistant. The time taken to attain the quasi-equilibrium $(t<17 \mathrm{~h})$, in general, also infers that the adsorption process is possibly film diffusion-controlled [31]. Therefore, the adsorption of MB onto basic-treated human hair could be based on the following mechanisms: (i) film/external diffusion (slowest step), (ii) intraparticle diffusion (adsorption), and (iii) cooperative adsorption.

\subsection{Adsorption thermodynamics}

Figure 7 shows the removal of MB dye onto basic-treated adsorbent at different temperatures. Generally, the 


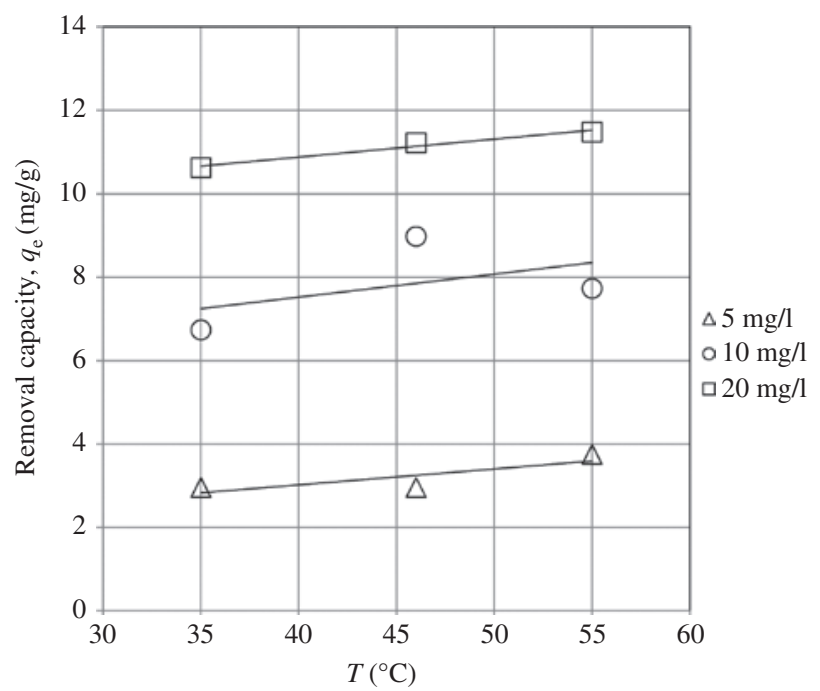

Figure 7: Effect of temperature on methylene blue removal by basictreated human hair adsorbent.

adsorption slightly increased with increasing temperature, indicating that the process is temperature-dependent and endothermic. The thermodynamics properties, i.e. enthalpy of adsorption $(\Delta H)$, Gibbs energy $(\Delta G)$, and entropy $(\Delta S)$ were calculated using the Gibbs expression as follows,

$$
\ln K=\frac{-\Delta G}{R T}=\frac{-(\Delta H-T \Delta S)}{R T}
$$

where, $K=C_{\mathrm{e}, \mathrm{a}} / C_{\mathrm{e}}$ is the equilibrium constant, $C_{\mathrm{e}, \mathrm{a}}(\mathrm{mg} / \mathrm{l})$ is the amount of dye adsorbed, $T(\mathrm{~K})$ is the absolute temperature of solution, and $R=8.314 \mathrm{~J} / \mathrm{mol} \cdot \mathrm{K}$ is the gas constant. The respective thermodynamics data are summarized in Table 4.

From Table 4, the adsorption of MB onto BH is exothermic at lower concentration, and becomes more endothermic as the concentration increases. The higher the

Table 4: Thermodynamics properties of methylene blue adsorption by basic-treated human hair adsorbent.

\begin{tabular}{lcccr}
\hline$C_{\mathrm{o}}(\mathrm{mg} / \mathrm{l})$ & $T(\mathrm{~K})$ & $\Delta G(\mathrm{~J} / \mathrm{mol})$ & $\Delta H(\mathrm{~J} / \mathrm{mol})$ & $\Delta S(\mathrm{~J} / \mathrm{mol} \cdot \mathrm{K})$ \\
\hline 5 & 308 & $-3.09 \times 10^{3}$ & -4153 & -3.46 \\
& 318 & $-3.05 \times 10^{3}$ & & \\
& 328 & $-3.02 \times 10^{3}$ & & \\
10 & 308 & $-2.18 \times 10^{3}$ & -611 & 5.10 \\
& 318 & $-2.24 \times 10^{3}$ & & \\
& 328 & $-2.29 \times 10^{3}$ & & \\
& 308 & $-4.59 \times 10^{2}$ & 5116 & \\
& 318 & $-6.58 \times 10^{2}$ & & \\
& 328 & $-8.21 \times 10^{2}$ & & \\
\hline
\end{tabular}

concentration the greater the energy is absorbed during the adsorption. This is in accordance with the adsorption behavior that increased with increasing temperature. Likewise, the adsorption system demonstrates an increasing disorder or randomness because of the accumulation of dye molecules on the surface as the concentration increases. It is shown by the positive $\Delta S(\Delta S=18.1$ $\left.\mathrm{J} / \mathrm{mol} \cdot \mathrm{K}, C_{0}=20 \mathrm{mg} / \mathrm{l}\right)$, which also signifies that the process (or system) is feasible [32]. In general, the negative values of $\Delta G$ indicate that the $\mathrm{MB}$ adsorption onto $\mathrm{BH}$ is spontaneous. However, the spontaneity of the process decreased with increasing concentration. For example, the $\Delta G$ increased from $-3.1 \times 10^{-3}$ to $-4.6 \times 10^{-2} \mathrm{~J} / \mathrm{mol}$ with increasing concentration from 5 to $20 \mathrm{mg} / 1$ at $35^{\circ} \mathrm{C}$. This could be partly due to the nature of cooperative adsorption, whereby a concentration gradient is required as the driving force for subsequent increase in capacity after reaching the quasi-equilibrium. Nevertheless, the spontaneity of the process slightly improved as temperature increases to $55^{\circ} \mathrm{C}$ at $C_{0}=20 \mathrm{mg} / \mathrm{l}(\Delta G$ decreased from $-4.6 \times 10^{-2}$ to $-8.2 \times 10^{-2} \mathrm{~J} / \mathrm{mol}$ ), signifying the positive effect of temperature as the driving force for adsorption at higher concentration [32, 33].

\section{Conclusion}

Human hair was used as an adsorbent for MB dye removal from water. All adsorbents, i.e. the untreated, $\mathrm{HNO}_{3}$ treated and $\mathrm{KOH}$-treated human hair samples exhibit an S-shaped isotherm, suggesting a cooperative adsorption. The basic-treated human hair (BH) displays a superior removal of MB compared to other two counterparts. The removal of residual oil covering the human hair surface by $\mathrm{KOH}$, possibly exposes the functional groups thus increasing the effective surface area and the removal performance. The maximum capacity of $\mathrm{BH}$ was recorded as $13.5 \mathrm{mg} / \mathrm{g}$. Further evaluation on the effect of time revealed a sudden increase in the adsorption capacity after a $17 \mathrm{~h}$ quasi-equilibrium for MB concentrations of 13 and $25 \mathrm{mg} / \mathrm{l}$. The mechanisms of adsorption could be summarized as: (i) external diffusion, (ii) adsorption, and (iii) cooperative adsorption. The adsorption process is endothermic and spontaneous with increasing temperature especially at high MB concentration.

Acknowledgments: This work was part of R. Md. Sudi's thesis for the fulfilment of a Master's degree (Safety, Health, and Environment). The award of Flagship Grant no. 03 G70 is gratefully acknowledged. 


\section{References}

[1] Gupta A. J. Waste Manage. 2014, 1, 1-7.

[2] LaTorre C, Bhushan B. Ultramicroscopy 2006, 106, 720-734.

[3] Velasco MVR, Dias TCDS, Freitas AZD, Júnior NDV, Pinto CASDO, Kaneko TM, Baby AR. Braz. J. Pharm. Sci. 2009, 45, 153-162.

[4] Zaini MAA, Alias N, Yunus MAC. Polish J. Chem. Technol. 2016, 1, 15-21.

[5] Zaini MAA, Zakaria M, Mohd-Setapar SH, Yunus MAC. J. Environ. Chem. Eng. 2013, 1, 1091-1098.

[6] Ming-Twang S, Lin-Zhi L, Zaini MAA, Zhi-Yong Q, Pei-Yee AY, in Advances in Environmental Research, Daniels JA, Ed., Nova Science Publishers Inc.: New York, 2015, Vol. 36, p. 217-234.

[7] Ifelebuegu AO, Nguyen TVA, Ukotije-Ikwut P, Momoh Z. J. Environ. Chem. Eng. 2015, 3, 938-943.

[8] Mahdavian L. Afr. J. Microbiol. Res. 2012, 6, 183-189.

[9] Hashem MA, Abdelmonem RM, Farrag TE. Alexandria Eng. J. 46, 2007, 205-213.

[10] Farrag TE, El-Haiwany MM. Alexandria Eng. J. 2009, 48, 355-364.

[11] Roh HG, Kim SG, Jung J. Korean J. Chem. Eng. 2014, 31, 310-314.

[12] Ming-Twang S, Zhi-Yong Q, Lin-Zhi L, Pei-Yee AY, Zaini MAA. In Advances in Chemistry Research, Taylor JC, Ed., Nova Science Publishers Inc.: New York, 2015, Vol. 23, p. 143-156.

[13] Zaini MAA, Cher TY, Zakaria M, Kamaruddin MJ, Mohd-Setapar SH, Yunus MAC. Desalin. Water Treat. 2014, 52, 3654-3662.

[14] Shu-Hui T, Zaini MAA. In Advances in Chemistry Research, Taylor JC, Ed., Nova Science Publishers Inc.: New York, 2016, Vol. 30, p. 19-34.
[15] Postai DL, Demarchi CA, Zanatta F, Melo DCC, Rodrigues CA. Alexandria Eng. J. 2016, 55, 1713-1723.

[16] Salman TA, Ali MI. Iraqi J. Sci. 2016, 57, 1-13.

[17] Rani MJ, Murugan M, Subramaniam P, Subramanian E. Indian J. Chem. Technol. 2016, 23, 22-30.

[18] Thangappan H, Parambathu AV, Joseph S. Desalin. Water Treat. 2016, 57, 21118-21129.

[19] Naushad M, Khan MA, Alothman ZA, Khan MR, Kumar M. Desalin. Water Treat. 2016, 57, 15848-15861.

[20] Sharma YC, Uma, Sinha ASK, Upadhyay SN. J. Chem. Eng. Data 2010, 55, 2662-2667.

[21] Dankers LM. Physical Analysis of Human Hair, University of Missouri: Rolla, 2007.

[22] Monteiro VF, Maciel A, Longo E. J. Therm. Anal. Calorim. 2005, 79, 289-293.

[23] Langmuir I. J. Am. Chem. Soc. 1918, 40, 1361-1403.

[24] Grant PG, Lemke SL, Dwyer MR, Phillips TD. Langmuir 1998, 14, 4292-4299.

[25] Parreira HC. J. Colloid Interface Sci. 1980, 75, 212-217.

[26] Robbins CR. Chemical and Physical Behavior of Human Hair, Springer-Verlag: Berlin, 2012.

[27] Lagergren S. Handlingar 1898, 24, 1-39.

[28] Ho YS, McKay G. Process Saf. Environ. Prot. 1998, 76, 183-191.

[29] Weber WJ, Morris JC. J. Sanit. Eng. Div. Am. Soc. Civ. Eng. 1963, $89,31-60$.

[30] Zaini MAA, Amano Y, Machida M. Desalin. Water Treat. 2014, 52, 6420-6429.

[31] Tang SH, Zaini MAA. Asia Pac. J. Chem. Eng. 2017, 12, 159-172.

[32] Zhi LL, Zaini MAA. Water Sci. Technol. 2017, 75, 864-880.

[33] Uma, Banerjee S, Sharma YC. J. Ind. Eng. Chem. 2013, 19, 1099-1105. 